\title{
Economic Valuation of Increased Malaria due to Climate Change: A South African Case Study
}

\section{Randall Spalding-Fecher ${ }^{1}$}

Energy and Development Research Centre, University of Cape Town

\section{Shomenthree Moodley}

Minerals and Energy Policy Centre, Johannesburg

\begin{abstract}
Malaria is one of the world's most serious and complex health problems. It is also one of the diseases identified as most likely to be affected by climate change, because transmission is sensitive to temperature and rainfall. The objective of this paper is to provide an initial economic valuation of the increased incidence of malaria due to projected changes in climate in South Africa, excluding costs and benefits of prevention and adaptation. We use market based economic valuation tools for morbidity, including cost of treatment and lost short term productivity, and report lost disability adjusted life years from malaria mortality due to climate change. We also discuss how human capital and willingness to pay approaches could be used for mortality valuation. The results show that the opportunity cost of increased morbidity from malaria would be between R277 million and R466 million in 2010, while the lost disability adjusted life years from increased mortality would be from 11 800 to 18300 years in that year.
\end{abstract}

JEL Q00

\section{INTRODUCTION}

Malaria is one of the world's most serious and complex health problems. More than 40 per cent of the world's population is at risk of malaria, with over 270 million cases per year and more than 1 million deaths (Murray \& Lopez, 1997; WHO, 1998). The impacts of malaria, however, go well beyond the immediate effects of the illness to affect economic growth and development. Controlling for factors such as geography, colonial history and isolation, countries with severe malaria had income levels in 1995 two thirds less than countries without malaria (Gallup \& Sachs, 1998). 
Malaria is also one of the diseases identified as most likely to be impacted by climate change, because transmission is sensitive to temperature and rainfall (Kovats, Menne, McMichael, Corvalan \& Bertollini, 2000). The burden on Africa, where the vast majority of deaths occur, is likely to be greatest.

While some analysis is available in South Africa on the increased risk of malaria from climate change, and the current illness costs of malaria, these two disciplines have not been brought together. The objective of this paper is to bridge the gap between the climate and malaria risk modelling in the South Africa Climate Change Country Study Vulnerability and Adaptation Assessment and the economic valuation of malaria in South Africa. Our purpose, therefore, is not to apply new valuation techniques through primary data collection, but to apply the valuation literature to this climate change risk.

We present a first order estimate of the cost of malaria from climate change, before adaptation has occurred. We use a three step methodology to estimate the economic impacts of increased malaria due to climate change:

- Estimate the number of excess cases of malaria due to climate change, based on:

- increased population at risk of contracting malaria because of climate change; and

- the share of population at risk that is likely to contract malaria (i.e. incidence ratios).

- Estimate the economic cost of malaria morbidity due to climate change, based on:

- The direct cost of treating the additional cases; and

- Short term productivity losses from patients or their caregivers being unable to work.

- Estimate the economic cost of malaria mortality due to climate change, based on:

- Lost work years due to premature death from malaria; and

- Willingness to pay for reduced risk of death, adapted from the international literature.

It is important to emphasise at the outset, however, that the uncertainties in each step of this process are quite significant. Even understanding the future population at risk depends on complex models of how climatic conditions impact malaria parasite and mosquito survival, how to translate very coarse global climate model results into higher resolution predictions for rural South Africa, and how population distribution will change as a result of increasing urbanisation. Each of these modelling processes adds another level of complexity and uncertainty. We have tried, therefore, where possible to express our assumptions and results in terms of ranges and to discuss where 
uncertainties are greatest. The second major challenge of this work is how to realistically describe an impact "before adaptation has occurred" - because, in reality, adaptation to malaria risks has already occurred in South Africa. Given that control programmes are already in place in South Africa, and have reduced the population at risk from much higher historical levels, these controls would still be expected to be present in the future. When we say 'before adaptation has occurred', then, we really mean before additional measures have been put in place, such as dramatically expanding existing programmes.

The next two sections introduce the relationship between malaria and climate change and the background of malaria in South Africa. Section 4 presents our analysis of increased malaria morbidity and mortality. Sections 5 and 6 present our estimates of the economic impacts of morbidity and mortality, respectively, followed by a short summary and conclusion.

This paper also forms part of a larger study on economic valuation of climate change impacts on South Africa (Turpie, Winkler, Spalding-Fecher \& Midgley, 2001).

\section{MALARIA AND CLIMATE CHANGE LINKS}

Malaria risk is governed by a large number of environmental factors, many of which are seasonal, that affect the intensity of transmission and duration of the high risk season. Of all factors, climate is considered the most important limiting factor (Craig \& Sharp, 2000). Temperature, rainfall and humidity all play a role in determining survival of the vector - the anopheles mosquito - and the parasite itself. Of course, the actual risk of malaria will be affected by adaptation measures, including eradication programmes and public health interventions. Some of these are already in place to combat existing malaria risk. The purpose of this analysis, however, is to make a first order estimate of the increased cost of malaria from climate change, before additional adaptation has occurred.

Recent modelling of the impact of climate change on malaria distribution suggests that an additional 260 to 320 million people could be at risk by 2080 because of climate change (Martens, Kovats \& Nijhof, 1999). The areas where this change will be most dramatic are those where malaria transmission is currently marginal because of low temperature or insufficient rainfall, among other factors. This means that, while tropical African countries, where malaria risk is already very high, will not see increased risk due to climate change, highland areas in Eastern and Southern Africa, or areas with currently 
insufficient rainfall, could see significant increases in populations at risk (Kovats et al., 2000).

\section{MALARIA IN SOUTH AFRICA}

Malaria was intensely endemic to large areas of South Africa before the 1940s, including in major urban areas such as Pretoria and Durban, with more than 22 000 people dying in an epidemic in KwaZulu-Natal in 1932 (Sharp, Craig, Curtis, Mnzava, Maharaj \& Kleinschmidt, 2000). Systematic control measures in the following decades, including indoor insecticide spraying and active treatment of the disease, reduced the areas of risks for the disease to the northeastern borders of the country (Craig \& Sharp, 2000). Current high risk areas include 24 rural districts in the easternmost parts of Northern Province, Mpumalanga and KwaZulu Natal (Sharp et al., 2000). Through the early 1970s, cases had dropped to less than 500 per year with almost no fatalities.

This trend, however, has reversed since the 1970 s, with exponential growth in incidence of malaria for the last fifteen years. The number of cases jumped from 4693 in 1991, to 27035 in 1996, to 61253 in 2000 (DOH, 2000). Malaria experts point out that this increase is not due to changes in climate (e.g. excessively warm and wet years), however, but to increasing drug resistance, an influx of migrants from neighbouring countries where malaria is not controlled, and reduced spraying with insecticides such as DDT (Craig \& Sharp, 2000; Sharp et al., 2000).

\section{IMPACT OF CLIMATE CHANGE ON MALARIA INCIDENCE IN SOUTH AFRICA}

The first step in assessing the economic costs of increased malaria due to climate change is to estimate how many more people will get malaria, and how many more will die from it. This is based on both the increased population that it as risk due to future climatic changes in South Africa, as well as the likelihood that people in high risk areas will contract malaria or die from it.

\subsection{Increased population at risk}

The South African Country Study for Climate Change (SACSCC) Vulnerability and Adaptation (V\&A) Assessment included a chapter on malaria (Craig \& Sharp, 2000). In this analysis, researchers from the Medical Research Council applied a model that linked temperature (both average and minimum winter) and rainfall to climatic suitability for malaria transmission (Craig, Snow \& 
leSueur, 1999). This model was checked against historical data for a number of African countries to verify that it gave a reasonable estimate of the area in which malaria is endemic (i.e. stable transmission every year).

The science of climate change involves the use of sophisticated models of the global atmosphere, oceans and landmasses that link changes in atmospheric concentrations of greenhouse gases. The models at a global scale are called 'global circulation models', and give fairly coarse resolution predictions - in other words, they can only identify the change in rainfall, temperature, etc. for a fairly large unit area. To get consistent results, the various studies within the V\&A assessment (e.g. health, agriculture, forestry) all used the same future climate scenarios - the Hadley Centre global circulation models (see Met Office, 2000). In addition, the Hadley models used present two scenarios of future climate - one that includes the effect of sulphates on climate change and one that does not. Contrary to greenhouse gases such as carbon dioxide and methane, sulphates actually exert a local or regional cooling effect on the atmosphere. However, sulphates only stay in the atmosphere for a short time, so in the context of tighter sulphur emissions standards in South Africa (RSA, 2001), they are unlikely to be an important influence over the climate in coming decades. For this reason, we use the results from the V\&A study that exclude the impact of sulphates (Midgley, 2001).

As we mentioned before, one difficulty with these global circulation models is that their resolution is quite coarse. Predictions of current average temperature in South Africa from the Hadley models, when compared to more detailed local climate models (Hutchinson, Nix, McMahan \& Ord, 1995; Schultze, 1997), for example, vary by 2 to 4 degrees Celsius in many areas (Craig \& Sharp, 2000). As Craig and Sharp (2000) note in the V\&A study on health impacts, "the difference between the present [Hadley] models and actual climate are therefore much greater than the difference between the present and future [Hadley] scenarios." An additional challenge is that the population growth projections for 1996 to 2010 in the V\&A Assessment are based on 1990 to 1995 actual growth rates. Most of the current research on demographics in South Africa, however, suggests that deaths due to HIV/AIDS will significantly slow population growth rates in the coming decades (SSA, 2000). For example, national population grew at 2.2 per cent per year from 1991 to 1999 (SSA, 1998,2000 ), but for 2000 to 2010, HIV/AIDS deaths could reduce projected population growth from 2.3 per cent to 1.5 per cent (ABSA Group Economic Research, 2001). The United Nations projects population growth rates of under 1 per cent in 2000-2005, falling to -0.2 per cent in 2010-2015 (UN Population Division, 2000). On the other hand, as the share of the population that is immuno-compromised due to HIV/AIDS increases, so will the susceptibility to 
contracting illnesses such as malaria. The predicted populations at risk from the Craig and Sharp (2000) study should therefore be seen as an upper bound.

The projected populations at risk based on the local climate models and the Hadley model with and without climate change are presented below in Table 1 below.

Table 1 Estimated populations at risk based on different climate models and climate scenarios

\begin{tabular}{|l|r|r|c|c|c|}
\hline & \multicolumn{2}{|c|}{ Present climate } & \multicolumn{3}{c|}{ Hadley model no sulphates } \\
\hline & Hutchinson & Schultze & $\begin{array}{l}\text { Present } \\
\text { climate }\end{array}$ & $\begin{array}{c}\text { Future } \\
\text { climate }\end{array}$ & Increase \\
\hline 1995 & $9,101,875$ & $7,854,638$ & $5,049,654$ & & \\
\hline 1996 & $8,603,783$ & $7,819,266$ & $4,912,228$ & & \\
\hline 2000 & $10,662,127$ & $9,241,847$ & $5,977,839$ & & \\
\hline 2005 & $10,622,127$ & $10,966,172$ & $7,174,761$ & $30,637,710$ & $23,462,949$ \\
\hline 2010 & $15,133,780$ & $13,211,391$ & $8,703,941$ & $36,300,636$ & $27,596,695$ \\
\hline
\end{tabular}

Source: (Craig \& Sharp, 2000)

Note: The first two columns - 'Present climate' - are from detailed models of the current SA climate (Hutchinson et al., 1995; Schultze, 1997), with growth in population at risk only due to growth in population. 'Hadley model no sulphates' are projections based on the climate outputs (e.g. temperature and rainfall) from the Hadley climate models in each year. The 'future climate' column is based on Hadley model projections of climate outputs in the future given continue climate change.

All of the climate models, including those based on local data such as Hutchinson and Schultze, overestimate the current population at risk, because of the adaptation measures already in place, as mentioned earlier. A more detailed assessment suggests that only about 3 million people live in districts where the malaria cases are greater than 1 per 1000 people per year (Sharp et al., 2000). To try to reflect what prevention measures are already in place, we use the percentage change in population at risk in the climate models, rather than the absolute numbers.

The Hadley models predict that climate change will increase the population at risk of malaria by 417 per cent in 2010 - primarily because the malaria risk area in the future includes the heavily populated Witswatersrand area. Note that, compared to the Hutchinson and Schultze data, the Hadley model underestimates the present population at risk - although the Hadley model estimates are closer to more detailed studies mentioned above (Sharp et al, 
2000; Tren, 2001). We have conservatively assumed almost no net population growth overall between 2000 and 2010 (UN Population Division, 2000), and applied the 417 per cent increase to the 3 million based on the detailed analysis of population at risk in 1999, for a total population at risk in 2010 of 12.6 million. In other words, climate change by 2010 would put an additional 9.6 million people at risk of contracting malaria.

\subsection{Increased morbidity and mortality}

\subsubsection{Methodology}

A wide variety of socio-economic, environmental and health factors influence the share of the population at risk that will actually contract malaria. As many studies of climate change and disease point out, the spread of vector bome diseases could spur new efforts to control or eradicate these diseases. In this study, however, we have explicitly not considered adaptation beyond what is already happening - although this is clearly an important area for future work. For this reason, our best reference point for malaria incidence ratios is to look at current cases of malaria relative to populations at risk. As described in the previous section, however, establishing the size of population at risk is not a simple matter. Based on the detailed estimates by Sharp et al. (2000), 3 million people were in high risk areas in 1999. Given 51535 cases of malaria in 1999 ( $\mathrm{DOH}, 2001)$, this means an incidence ratio of 17.1 per 1000 persons at risk. Note that this is not a general incidence ratio for South Africa, but only for those relatively small areas with high risk. For comparison, the incidence ratio in high risk areas (defined as areas where climatic suitability is $>0.5$ ) in Southern Africa is 11 cases per 1000 (Snow, Craig, Deichmann \& Marsh, 1999).

Under the climate scenarios explained earlier, the future change in climate would, in theory, make some major metropolitan areas in South Africa climatically suitable for stable malaria transmission. In practice, however, the incidence ratios in these areas - even without significant new prevention programmes - will be much lower than in poorer rural areas. To be conservative, we have used a range of incidence ratios, which are 25 per cent to 50 per cent lower than the current incidence in rural areas.

For mortality estimates, we used the average share of malaria cases resulting in death in the last three years in South Africa, or 0.7 per cent of cases (DOH, 2000). The Southern African average is 1 per cent (Snow et al., 1999). 


\subsubsection{Results}

The projected incidence ratio for 2010 is between 8.6 and 12.8 cases per 1000 . Applied to a population at risk of 12.6 million, this means 107000 to 161000 cases. Only the cases due to the increased area of climatic suitability, however, can be attributed to climate change. Applying these ratios to the 9.6 million who are at risk due to climate change, therefore, we have 82000 to 126000 additional cases of malaria due to climate change. Out of these additional cases, we would expect 600 to 900 deaths per year, given current mortality rates.

\section{VALUATION OF INCREASED MORBIDITY}

To place an economic value on increased morbidity, we have used two tools: the cost of treatment and the opportunity cost of lost work days. The treatment cost is the full costs of treating a particular illness with one or more treatment regimens. Treatment cost if often used as an input to cost effectiveness analysis, where the input costs of two alternative treatment regimens are compared with their health outcomes - in other words, how much it costs to avoid illness, death, or further medical treatment (Zweifel \& Breyer, 1997). The opportunity cost of being ill can be measured in terms of lost income from being unable to work. Treatment cost is often called the 'direct' cost of an illness, while lost productivity or opportunity cost is referred to as the 'indirect' cost. What these two methods do not address, however, is the actual physical and emotional pain and suffering that accompanies illness, or the impacts this has on quality of life and society more broadly. These measures, therefore, can only serve as a lower bound for the economic value of morbidity.

\subsection{Treatment costs}

\subsubsection{Methodology}

We are interested in the direct and indirect costs of medical treatment for patients contracting malaria. We must assume that the costs of treating the additional future patients due to climate change will be similar to the cost of treating patients today in real terms.

The most detailed recent study on the costs of treating malaria in clinics and hospitals in South Africa is work by Justin Wilkins at University of Cape Town (Wilkins, 1999). This study looked at the costs of medical personnel, drugs, and all hospital costs associated with alternative therapies for first line malaria treatment. Building on this work, Richard Tren of the UK Institute of Economic Affairs analysed the costs of malaria treatment in South Africa, 
including the costs of the Malaria Control Programme (Tren, 2001). The Malaria Control Programme sends health care workers into the field to identify, test and treat malaria cases in rural areas, as well as provide preventive measures such as insecticide spraying. At least part of the costs of this programme should also be included in treatment costs for malaria, since much of the treatment occurs in the field. It was not possible to identify the share of personnel expenditure (the largest item in the programme budget) that was devoted to treatment. Expenditure for insecticides was subtracted, however, since this is clearly a preventive measure.

\subsubsection{Results}

Table 2 shows the cost per patient of treatment in hospital and in the field. The malaria control programme is an order of magnitude greater that hospital costs but this is to be expected because 42 per cent of cases are diagnosed and treated in the field, while another 32 per cent are treated as outpatients at clinics and hospitals (Tren, 2001). A more detailed allocation of the Malaria Control Programme costs to treatment versus prevention would improve this estimate.

Table 2 Treatment costs per malaria patient (Rands)

\begin{tabular}{|l|r|r|r|}
\hline & 1996 & 1997 & 1998 \\
\hline $\begin{array}{l}\text { Cost of treating and hospitalising } \\
\text { patients }\end{array}$ & 300 & 276 & 260 \\
\hline Malaria Control Programme & 2301 & 2925 & 3016 \\
\hline - less preventive expenditures & 190 & 242 & 249 \\
\hline Total (current year R) & 2410 & 2959 & 3026 \\
\hline Total (2000 R) & 3097 & 3502 & 3352 \\
\hline
\end{tabular}

Source: (Tren, 2001), own analysis

The average cost per patient ranges from $R 3097$ to $R 3502$. Table 3 shows the results for the direct costs of treatment, ranging for $R 253$ to $R 429$ million. Note that this is only the costs of the treating the excess cases due to climate change.

Table 3 Treatment costs of excess malaria cases due to climate change, 2010

\begin{tabular}{|l|r|r|}
\hline & Low & High \\
\hline Cost per patient (R2000) & 3097 & 3502 \\
\hline Number of cases & 81700 & 122500 \\
\hline Total cost (R2000 million) & 253 & 429 \\
\hline
\end{tabular}




\subsection{Lost short term productivity}

\subsubsection{Methodology}

Lost productivity due to illness depends both on wages and days out of work. For wages, Tren (2001) analysed the average wage of employed persons in districts in the three provinces with endemic malaria. Weighted average wages for those employed were R193 per day in 1997, which is equivalent to R224 per day in 2000 (SARB, 2001). Only 47 per cent of the population of these districts, however, had formal employment, while a further 12 per cent were employed in the informal sector. As Tren correctly points out, even people who are not formally employed in rural areas would contribute to subsistence agriculture, so it is reasonable to use an agricultural wage ( $R 36$ per day adjusted to 2000 wages) for the unemployed and informally employed as a proxy for their lost productivity.

For the 11 per cent of malaria cases that occur in children under 5, a caregiver will need to take time away from work during the illness. Even for those in the 5 to 15 age group ( 30 per cent of reported cases), it is likely that either a caregiver will have to take time away or that some of these youth would have been involved in supporting subsistence activities. For these reasons, we assume that all malaria cases will result in lost productivity.

Days of lost work depends on the severity of the case and treatment regimen, which are also affected by the age of the patient. Children under 5, for example, are always hospitalised for 4 days treatment, so all of these cases will result in at least 4 lost productive days. For children ages 6 to 15 , we assume that a caregiver will need to take part of the time off work for an average of 2 days. For cases ages 16 and up, the days lost depends on severity. Cases identified actively (i.e. through field workers in the Malaria Control Programme) will by definition not be as severe, with only one day lost. For those that come to a clinic or hospital, 55 per cent are assumed to be treated as outpatients with oral medication and 40 per cent will be hospitalised and given oral medication both of these groups lose 4 days productive time. For the 5 per cent of hospital cases that require intravenous quinine, 7 days of productive time will be lost (Tren, 2001). For each of these groups, we apply the share of employed, unemployed, and informally employed to match wages to days of lost productivity.

\subsubsection{Results}

Table 4 below shows the lost productivity per case, depending on how the case is treated and the employment status or wage of the patient. Using this table 
and the share of cases falling into the different categories within the matrix, we calculate a weighted average productivity loss of R299 per case. This implies a total lost productivity of R24 to 37 million from malaria cases due to climate change.

Table 4 Lost productivity per case, based on case type and employment status (R2000)

\begin{tabular}{|c|c|c|c|}
\hline Types of malaria case & Employed & $\begin{array}{l}\text { Unem- } \\
\text { ployed }\end{array}$ & $\begin{array}{c}\text { Informally } \\
\text { employed }\end{array}$ \\
\hline Age $<5$ years $*$ & & \multicolumn{2}{|c|}{142} \\
\hline Age $5-15$ years* & 449 & 71 & 71 \\
\hline Age $>15$ years & & & \\
\hline $\begin{array}{l}\text { identified by fieldworkers; oral } \\
\text { treatment given in the field }\end{array}$ & 224 & 36 & 36 \\
\hline $\begin{array}{l}\text { - Oral treatment as outpatients or in } \\
\text { hospital }\end{array}$ & 897 & 142 & 142 \\
\hline - Intra-venous treatment in hospital & 1570 & 249 & 249 \\
\hline
\end{tabular}

*this value captures the lost productivity of the person caring for the sick child

\section{VALUATION OF INCREASED MORTALITY}

Valuation of the loss of life is one of the most difficult areas of environmental and health economics. Whether it is appropriate to equate a life, or the prolonging of life, with money, is an important ethical and moral question. The critical issue, however, is that every public decision on spending related to health (or any private expenditure) does implicitly place a value on statistical lives - or, more precisely, on the statistical risk of reduced length of life. This is particularly true with decisions on public expenditure to reduce health risks: policy makers need some kind of metric to help weigh decisions about what type of investments to make and how their benefits may outweigh their costs.

There are two broad approaches to dealing with valuation of reduced life expectancy. The first is based on assessing individuals' willingness to pay to avoid risks, or willingness to accept compensation for taking on risks. This is based on basic principles in economics that individual preferences are the most important source of value, and that welfare, as perceived by the individual, is the appropriate metric (Zweifel \& Breyer, 1997). If we know what all individuals in society are willing to pay to avoid a certain risk, we then know exactly how much society should spend on avoidance investments. The difficulty, however, is how to elicit these preferences accurately. The most 
direct approach is the contingent valuation method (CVM), where survey respondents are asked hypothetical questions about their willingness to pay for reduced risks (or accept compensation for those risks) (Klose, 1999). The practical challenges in designing these studies, and the cost of executing them, has meant that relatively few studies have been conducted in developing countries. The only way to utilise this approach in many developing countries, therefore, is to use values from industrialised countries and somehow adjust them for local conditions (discussed in more detail below). This limits our ability to choose between alternative approaches, such as willingness-to-pay versus willingness-to-accept.

The second method is called the 'human capital approach', and equates the value of the lost statistical life with the net present value of lost future contribution to Gross National Product (Zweifel \& Breyer 1997). In other words, when society loses this person, they lose the value added (e.g. wages less personal consumption) that the person would have contributed to the economy for the remainder of their natural life. There are obvious problems with this approach, most importantly that, from an ethical standpoint, there is no reason that an individual's value (to themselves or to others) should be related to their economic output (Zweifel \& Breyer, 1997; Fankhauser, Tol \& Pearce, 1998). The possibility that the life of a pensioner or someone who is disabled could be zero (or negative) goes against other social values - although if we use average GDP per capita for the whole population, we can avoid this problem within a given country. Worse yet, GNP is not necessarily an appropriate measure of social welfare in any case (Daly \& Cobb, 1989). At best, the human capital approach should only provide an absolute minimum estimate of economic costs (Dixon, Scura, Carpenter \& Sherman. 1994). Despite these serious theoretical drawbacks, the practical reality facing researchers and policy makers in developing countries is that willingness to pay studies simply are not available. The human capital approach is relatively simple to implement, and so it still used in many developing countries (Parikh, Parikh, Muralidharan \& Hadker, 1994). Moreover, it avoids some of the serious problems with transferring willingness to pay values across countries (discussed in more detail below).

Because of the ethical issues related to this type of analysis, many health economists use measures such as 'Disability Adjusted Life Years' (DALYs) lost. This is a standard health care analytical tool that combines years of life lost and years of life disabled, measured relative to incidence of the illness. Although we present the economic analysis below to illustrate how use to the two major types of valuation tools, we have also chosen to limit our final results to DALYs lost because of the ethical issues surrounding mortality valuation. 


\subsection{Human capital: lost productive years of life}

\subsubsection{Methodology}

We use two approaches to estimating human capital. The first is to estimate the average years of life lost in South Africa and the contribution to economic output that the average individual would have made over those years based on GDP per capita. This gives a direct estimate of years of productive life lost. The second possibility is to use the measure of DALYs lost per case and GDP per capita to then place a value on those DALYs. While there are no DALY values for malaria in South Africa, the Global Burden of Disease study estimates that, for sub-saharan Africa, DALYs for malaria are 0.145 per incidence of illness (Murray \& Lopez 1997). This takes into account the age at death, years lost, and a discount rate of 3 per cent for future years lost.

\subsubsection{Results}

For lost work years, age at death is based on Tren's (2001) reporting of deaths from malaria in Mpumalanga in 1997 and 1998, where the average age at death was 22.9 years. According to the UNDP's Human Development Report, life expectancy in South Africa is 54.7 years (UNDP, 1999), so this means a loss of 32 years of economically active life. If the mortality rate for malaria is 0.7 per cent, then the DALYs lost per incidence of malaria is $0.149^{2}$ (using a 3 per cent discount rate for future years as in Murray \& Lopez, 1997).

Because we are evaluating the impacts of deaths in 2010, we should use per capita GDP in 2010, which is estimated by ABSA Group Economic Research (2000) as R22 360 (in 2000 Rands).

Table 5 summarises the range of DALYs lost per incidence of malaria, and the economic valuation using GDP per capita.

Table 5 DALYs lost and economic valuation for malaria mortality using GDP per capita, 2010

\begin{tabular}{|l|r|r|}
\hline & Low & High \\
\hline DALYs lost per case & 0.145 & 0.149 \\
\hline Total DALYs lost & 11800 & 18300 \\
\hline Lost economic output (R2000 million) & 265 & 408 \\
\hline
\end{tabular}




\subsection{Willingness to pay and benefits transfer}

\subsubsection{Methodology}

As discussed above, using contingent valuation to determine willingness to pay relies on large scale surveys on individual to ask them to evaluate what they would pay to avoid a certain additional risk, or what they would accept as compensation for that risk. Where primary research is not available in a given country, as is the case for many developing countries, we can adapt these values using the concept of 'benefits transfer'. With benefits transfer, we use the relative GDP per capita of the two countries to adjust the valuations. In other words, if we want to apply a WTP value to a country with one tenth the per capita income, then would should divide the WTP value by 10 . The problem with this approach is that, if we use it to place a value on the mortality risk, it appears that we are again setting people's value equal to their economic output. This would mean that people in poor countries are worth less than those in rich countries (Ekins, 1995). This has provide particularly problematic in global valuation exercises such as those for the potential damages from climate change (Fankhauser, Tol \& Pearce, 1997). While economists have proposed ways to address this problem (Fankhauser et al, 1997), this study does not have to tackle the intemational dimension of the problem because it looks only at domestic health impacts. We present the below for illustrative purposes only.

\subsubsection{Results}

A survey of economic valuations of health risks by Zweifel and Breyer (1997: 40) found that the value of a statistical life can vary greatly, in part because "considerable risk reductions of about $1: 10^{3}$ do not call forth a substantially larger willingness to pay then reductions of around $1: 10^{5}$ to $1: 10^{6 m}$. For studies that looked a higher risks $\left(1: 10^{3}\right)$, values for two studies were between 120 and 300000 US dollars (2000 dollars)(cited in Zweifel \& Breyer, 1997). This is much lower than studies done for lower risks, where values of $\$ 1$ million or more were common. In the case of malaria, however, the risk of dying is on the order of $1: 10^{5}$ for those in endemic areas. Zweifel and Breyer also look at valuation studies based on observed consumer behaviour - for example, how much additional wages people are willing to accept to compensate for more dangerous work and how much consumers will spend on purchases like smoke detectors, homes in areas with better air quality, or choices they make about driving speed and use of seat belts. Values from the wage risk studies may exceed $\$ 1$ million, and different studies often differ by several orders of magnitude. Values from consumer behaviour studies tend to range from $\$ 300000$ to $\$ 900000$ per statistical life. 
Our conclusion is that; given the lack of study in South Africa (or Africa) on these issues and the uncertainties in how comparable the overseas studies are, it is difficult to apply these results to the present analysis. For illustrative purposes, we could assume a range of $\$ 300000$ to $\$ 1$ million. When adjusted for 2000 exchange rates (SARB, 2001) and relative GDP per capita between the US and South Africa (World Bank, 2000), this means a total valuation of mortality from malaria due to climate change of R360 million to R1 700 million.

\section{CONCLUSIONS}

Table 6 below summarises the direct and indirect economic costs of increased risk of malaria due to climate change, but only provides a valuation for morbidity. Based on the assumptions and analysis described in this study, the opportunity cost of increased morbidity from malaria would be between R277 million and R466 million in 2010. Because we are using market values for both morbidity - in other words, direct opportunity costs of lost time, treatment costs, and lost future productivity - and have not included a monetary measure of the increased mortality, these figures should be seen as an absolute minimum estimate of damages.

Table 6 Summary of opportunity costs of increased malaria due to climate change in 2010 ( 2000 Rands)

\begin{tabular}{|l|r|r|}
\hline \multicolumn{1}{|c|}{ Category } & \multicolumn{2}{c|}{ Damages } \\
\hline & Low & High \\
\hline Opportunity cost of excess morbidity & & \\
\hline Cost of treatment (R million) & 253 & 429 \\
\hline Productivity losses (R million) & 24 & 37 \\
\hline Total & 277 & 466 \\
\hline Mortality impact & & \\
\hline Disability adjusted life years lost (DALYs) & 11800 & 18300 \\
\hline
\end{tabular}

One of the most important conclusions from this work is the need to understand both the costs and effectiveness of prevention measures - as a subcategory of what are referred to in the climate change literature as adaptation measures. As Craig and Sharp (2000) point out, for malaria to become endemic in Pretoria again would require an almost complete breakdown of the public health system and malaria control measures. There will clearly be some adaptation and increased need for preventive measures. On the other hand, the exponential growth of malaria cases in the last decade clearly indicates the challenge facing 
costing study, that clearly identifies the potential effectiveness of increased malaria control measures over lager parts of the country, as well as their cost, is the essential next step for policy development for malaria and climate change.

\section{ENDNOTES}

1 This research was supported by USAID and administered by the Joint Center for Political and Economic Studies Inc. under a subcontract agreement from Nathan Associates Inc. Comments and inputs from Marlies Craig, Jane Turpie, Harald Winkler, Mampiti Matete, James Blignaut, and Jan van Rensburg are greatly appreciated. All errors remain solely the responsibility of the authors.

2 This also includes the weighted average of 2.7 days of disability lost per case, adjusted by 60 per cent.

\section{REFERENCES}

1 ABSA GROUP ECONOMIC RESEARCH (2001) "Long-Term Prospects for the South African Economy: 2001-2015", Johannesburg, ABSA.

2 CRAIG, M.H. \& SHARP, B.L. (2000) "Health Section. Part 1: Malaria. South African Country Study on Climate Change Vulnerability \& Adaptation Assessment", Pretoria, Department of Environmental Affairs \& Tourism.

3 CRAIG, M.H., SNOW, R.W. \& LESUEUR, D. (1999) "A Climate-Based Distribution Model of Malaria Transmissions in sub-Saharan Africa", Parasitology Today, 15: 105-111.

4 DALY, H.E. \& COBB, J.B., JR. (1989) For the Common Good: Redirecting the Economy Towards Community, The Environment and a Sustainable Future, Boston, Beacon Press.

5 DIXON, J.A., SCURA, L.F., CARPENTER, R.A. \& SHERMAN, P.B. (1994) Economic Analysis of Environmental Impacts. London, Earthscan.

6 DOH (Department of Health) (2000) Statistical Notes, 2(17), Pretoria.

7 DOH (Department of Health) (2001) Malaria Cases per Month (1999. 2001), Pretoria.

8 EKINS, P. (1995) Rethinking the Costs Related to Global Warming. A Survey of the Issues. Environmental and Resource Economics 5: 1-47.

9 FANKHAUSER, S., TOL, R.S.J. \& PEARCE, D. (1997) "The Aggregation of Climate Change Damages: A Welfare Theoretic Approach", Environment and Resource Economics, 10: 249-266.

10 FANKHAUSER, S., TOL, R.S.J. \& PEARCE, D. (1998) "Extensions and Altematives to Climate Change Impact Valuation: On the Critique of 
IPCC Working Group III's Impact Estimates" Environment and Development Economics: 59-81.

11 GALLUP, J.L. \& SACHS, J.D. (1998) The Economic Burden of Malaria, Cambridge, Massachusetts, Center for International Development at Harvard.

12 HUTCHINSON, M.F., NIX, H.A., MCMAHAN, J.P. \& ORD, K.D. (1995) Africa - a Topographic and Climatic Database, CD-ROM.

13 KLOSE, T. (1999) "The Contingent Value Method in Health Care: Review", Health Policy 47: 97-123.

14 KOVATS, R.S., MENNE, B., MCMICHAEL, A.J., CORVALAN, C. \& BERTOLLINI, R. (2000) Climate Change and Human Health: Impacts and Adaptation, Geneva, World Health Organisation.

15 MARTENS, P., KOVATS, R.S. \& NIJHOF, S. (1999) "Climate Change and Future Populations at risk of Malaria" Global Environmental Change 9: S89-S107.

16 MET OFFICE (2000) "Climate Change: An Update of Recent Research from the Hadley Centre. Bracknell, Met Office, Hadley Centre for Climate Prediction and Research.

17 MIDGLEY, G.F. (2001) Biophysical Impacts of Climate Change in South Africa, Cape Town, National Botanical Institute.

18 MURRAY, C.J. \& LOPEZ, A.D. (1997) "Mortality by Cause for Eight Regions of the World: Global Burden of Disease Study", Lancet 349: 1269-76.

19 PARIKH, K., PARIKH, J., MURALIDHARAN, T. \& HADKER, N. (1994) "Valuing Air Pollution in Bombay", Bombay, Indira Gandhi Institute for Development Research.

20 RSA (Republic of South Africa) (2001) "Technical Background Document for the Development of a National Ambient Air Quality Standard for Sulphur Dioxide", Government Gazette, Vol 432, No. 22134, 1 June 2001. Pretoria, Department of Environmental Affairs \& Tourism.

21 SOUTH AFRICAN RESERVE BANK (2001) Quarterly Bulletin, Pretoria, SARB.

22 SCHULTZE, R.E. (1997) South African Atlas of Agrohydrology and Climatology, Pretoria, Water Research Commission.

23 SHARP, B.L., CRAIG, M., CURTIS, B., MNZAVA, A., MAHARAJ, R. \& KLEINSCHMIDT, I. (2000) "Chapter 18. Malaria. Health Systems Trust" South African Health Review 2000, Durban, The Press-Gang.

24 SNOW, R.W., CRAIG, M.H., DEICHMANN, U. \& MARSH, K. (1999) "Estimating Mortality, Morbidity and Disability Due to Malaria among Africa's Non-Pregnant Population", Bulletin of the World Health Organisation, 77 (8): 624-40.

25 STATISTICS SOUTH AFRICA (1998) Statistical Release P0302. Pretoria, Statistics South Africa. 
26 STATISTICS SOUTH AFRICA (2000) Statistical Release P0302, Pretoria, Statistics South Africa.

27 TREN, R. (2001) "The Economic Costs of Malaria in South Africa: Malaria Control and the DDT Issue", Anopholes.com.

28 TURPIE, J., WINKLER, H., SPALDING-FECHER, R. \& MIDGLEY, G.F. (2001) "Economic Impacts of Climate Change in South Africa: A Preliminary Analysis of Unmitigated Damage Costs", Cape Town, Southern Waters Ecological Research \& Consulting \& Energy and Development Research Centre.

29 UN POPULATION DIVISION (2000) "World Population Prospects 2000 Revision" Microsoft excel tables (ESA/P/WP.165).

30 UNITED NATIONS DEVELOPMENT PROGRAMME (1999) Human Development Report 1999, New York, UNDP.

31 WILKINS, J. (1999) "A Cost Analysis of the Treatment of First-Line Uncomplicated Malaria in the Tonga District of Mpumalanga", Department of Pharmacology. Faculty of Health Sciences. Cape Town, University of Cape Town.

32 WORLD BANK (2000) World Development Report 2000/2001, Oxford, Oxford University Press.

33 ZWEIFEL, P. \& BREYER, F. (1997) Health Economics, Oxford, Oxford University Press. 